(1)

CrossMark

\title{
Influenza virus-induced lung injury: pathogenesis and implications for treatment
}

\author{
Susanne Herold ${ }^{1}$, Christin Becker ${ }^{1}$, Karen M. Ridge ${ }^{2}$ and G.R. Scott Budinger ${ }^{2}$ \\ Affiliations: \\ ${ }^{1}$ Dept of Internal Medicine II, Universities Giessen and Marburg Lung Center (UGMLC), Justus-Liebig \\ University, Member of the German Center for Lung Research (DZL), Giessen, Germany. \\ ${ }^{2}$ Pulmonary and Critical Care Medicine, Northwestern University, Chicago, IL, USA. \\ Correspondence: \\ Susanne Herold, Dept of Internal Medicine II, Universities Giessen and Marburg Lung Center, Klinikstr. 33, \\ D-35392 Giessen, Germany. \\ E-mail: susanne.herolddinnere.med.uni-giessen.de
}

ABSTRACT The influenza viruses are some of the most important human pathogens, causing substantial seasonal and pandemic morbidity and mortality. In humans, infection of the lower respiratory tract of can result in flooding of the alveolar compartment, development of acute respiratory distress syndrome and death from respiratory failure. Influenza-mediated damage of the airway, alveolar epithelium and alveolar endothelium results from a combination of: 1) intrinsic viral pathogenicity, attributable to its tropism for host airway and alveolar epithelial cells; and 2) a robust host innate immune response, which, while contributing to viral clearance, can worsen the severity of lung injury. In this review, we summarise the molecular events at the virus-host interface during influenza virus infection, highlighting some of the important cellular responses. We discuss immune-mediated viral clearance, the mechanisms promoting or perpetuating lung injury, lung regeneration after influenza-induced injury, and recent advances in influenza prevention and therapy.

@ERSpublications

We discuss novel aspects of virus- and immune-mediated lung injury and repair after influenza infection http://ow.ly/JGhC6

Received: Oct 072014 | Accepted after revision: Jan 072015 | First published online: March 182015

Support statement: S. Herold received funding from the German Research Foundation (SFB1021 C05, SFB-TR84 B2) and the German Federal Ministry of Research and Education (FluResearchNet grant 01 KI 1006M). G.R.S. Budinger and K.M. Ridge received funding from the National Institutes of Health (HL71643, ES015024, ES013995, HL092963 and HL71643, HL124664, respectively). Funding was also received for the study from the German Center for Lung Research (DZL) and the Veterans Administration. Funding information for this article has been deposited with FundRef.

Conflict of interest: None declared.

Copyright @ERS 2015 


\section{Introduction}

Seasonal influenza A virus (IAV) infection is the most common cause of pneumonia-related death in the developed world and mortality attributable to IAV infection can be much higher during pandemics. For example, during the 2009 pandemic, infection with IAV rose to the ninth leading cause of death in the USA $[1,2]$. IAV primarily targets airway and alveolar epithelial cells as they express the sialic acid residues that function as receptors for the virus, resulting in epithelial damage and the exudation of fluid and protein into the airways and alveolar space, threatening gas exchange [3-7]. Clinically, severe IAV infection can present with bilateral pulmonary infiltrates and hypoxaemia, which define acute respiratory distress syndrome (ARDS), and death from hypoxaemic respiratory failure is a major contributor to mortality [8-14]. The overall incidence of ARDS attributable to seasonal IAV infection has been estimated at 2.7 cases per 100 000 person-years and can account for $4 \%$ of all hospitalisations for respiratory failure during the influenza season [15]. We find it conceptually useful to consider the course of IAV infection in three stages, with the understanding that many of these processes occur simultaneously through the course of the injury. The first is viral infection of the airway and alveolar epithelium and its replication in these cells, during which strategies that limit viral entry or replication can prevent or attenuate the severity of the infection $[3,16,17]$. The second is the innate followed by the adaptive immune response to the virus, which is important for viral clearance but can also induce significant damage to the alveolar epithelium and endothelium [18, 19]. The third is the development of long-term immunity to the infecting viral strain accompanied by the resolution of infiltrates and regeneration of damaged lung tissue, during which there is an increased susceptibility to secondary bacterial infection (fig. 1) [20-22]. Influenza B viruses are morphologically similar to IAV;

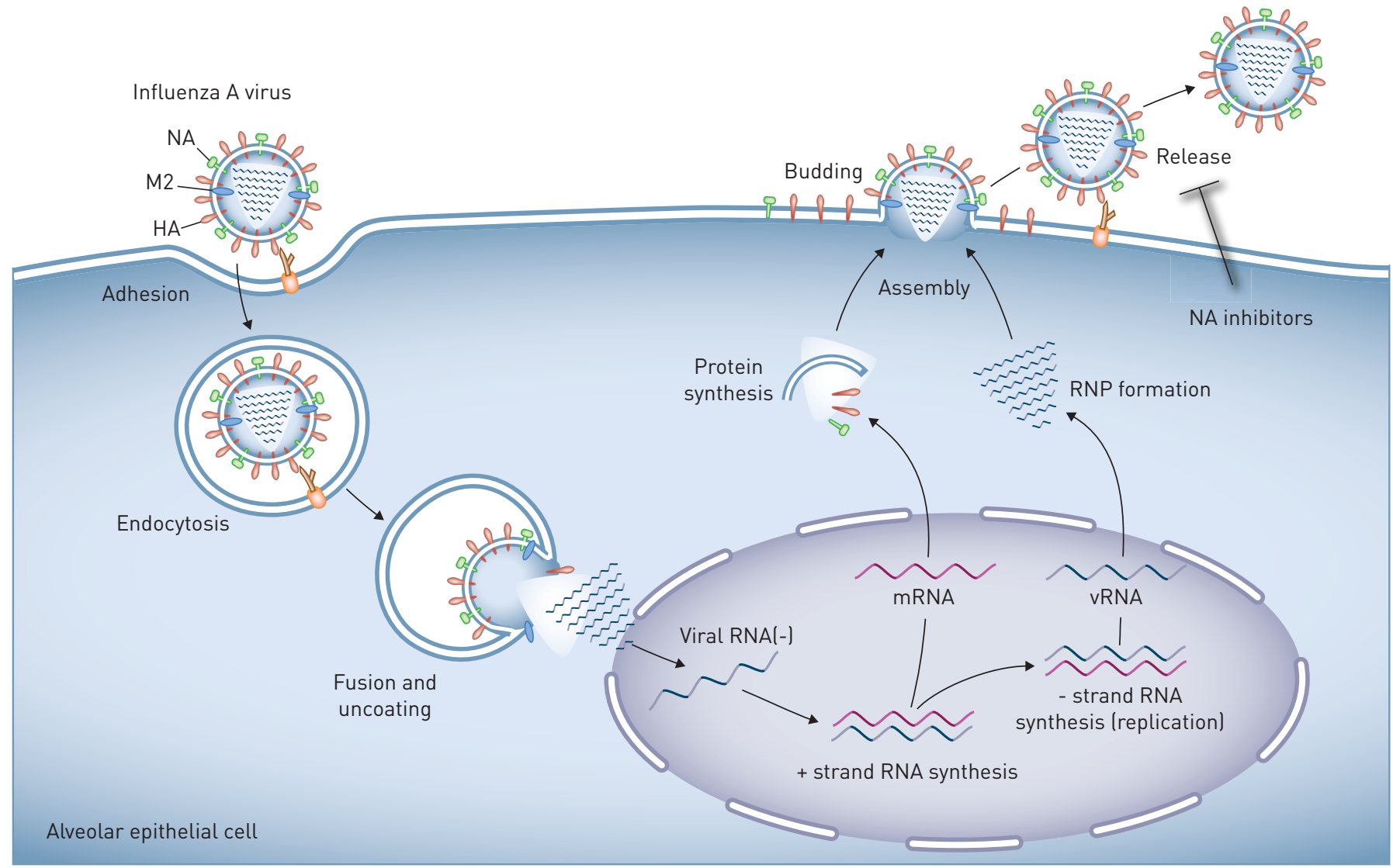

FIGURE 1 Replication of influenza A viruses in the lung epithelium. Binding of haemagglutinin (HA), expressed on the surface of the influenza virion, with sialic acid residues linked to cell surface glycans induces binding and fusion of the virion with the plasma membrane of the target cell. The HA in human viruses interacts with sialic acid residues linked to surface glycans via an $\alpha-2,6$ linkage, which is found in the upper and lower human airway epithelium and in alveolar type II cells. In contrast, the HA in avian viruses interacts with sialic acid residues in an $\alpha-2,3$ linkage. The virus then enters the cell via endocytosis or micropinocytosis and is trafficked to the lysosome where acidification activates the proton selective matrix protein-2 viral channel (M2), inducing membrane fusion and dissociation of the viral ribonucleoprotein (RNP) core, which is then transported to the nucleus where viral RNA replication occurs. Progeny viral RNP cores are generated in the cytosol and, with the viral surface proteins, HA and neuraminidase (NA), and other viral proteins, are concentrated in and near lipid rafts at the plasma membrane. Budding of these plasma membrane regions forms complete viral progeny, which is linked to the plasma membrane by HA/sialic acid interactions. Cleavage of sialic acid residues by neuraminidase releases the viral progeny so they are then free to infect other cells, which can be prevented by NA inhibitors. An alveolar epithelial cell is shown as an example but the life cycle is similar in the airway epithelium. 
however, perhaps because humans and seals are the only hosts for the influenza B virus, the genetic diversity of these viruses is limited to two circulating strains and infections are more common in children [23, 24]. A recent review of the literature suggested that the clinical presentation and complications of influenza $\mathrm{B}$ infections in children were similar to IAV; however, the authors noted that the literature was insufficient to exclude important differences [24]. For the remainder of this review, we limit our discussion to IAV except when explicitly noted.

\section{Infection of the lung epithelium and viral replication}

The influenza viruses are negative sense RNA viruses; therefore, successful viral replication requires the creation of sense messenger RNA from the viral genome by viral RNA polymerase [17]. The viral genome comprises eight RNA segments encoding a total of 11 proteins (table 1) [17]. A mature virion contains eight of these proteins surrounded by a protein envelope which includes the two viral antigenic determinants, hemagglutinin (HA) and neuraminadase (NA) $[6,28,32,51-55]$. The HA protein binds to sialic acid residues expressed on the airway or alveolar epithelium, triggering endocytosis of the virion [56]. Acidification of the endosome results in fusion of the viral HA with the endosomal membrane and activation of the M2 ion channel, allowing protons to enter the viral core to dissociate the ribonucleoprotein complex, which is then imported into the nucleus where viral replication occurs [57]. Virus assembly, budding and scission is co-ordinated at lipid rafts on the cellular plasma membrane [17]. After scission, the HA in the newly formed virion is bound to sialic acid receptors on the cell surface. These links are cleaved by NA, releasing the viral progeny, which then infects other cells or leaves the individual via aerosolised respiratory droplet secretions [17]. Amantadine and rimantadine target the M2 channel of the virus, but almost universal resistance to these agents now precludes their use [58]. Currently available agents to treat IAV infection, including oseltamivir and zanamivir, inhibit viral NA [58]. Therefore, they are most effective at limiting viral replication in the early stages of infection and in immunocompromised patients, and are less effective once an antiviral innate immune response is established $[59,60]$.

Seasonal IAV viruses cause infections in the winter months (December to April in the northern hemisphere and June to September in the southern hemisphere), when lower levels of humidity are suggested to facilitate transmission of the virus [61-63]. Annually, IAV strains with different antigenicity due to mutations in the HA and NA genes (antigenic drift) circulate in the northern hemisphere. Novel, re-assorted IAV strains are thought to emerge from persistent viral reservoirs in regions where viral incidence is less seasonal and interactions between humans and other species harbouring different IAV strains (primarily poultry and pigs) are more common. In this context, the segmented viral genome provides a continuous source of genetic diversity; when a single cell is infected by two viral strains, genomic segments are easily interchanged to create different strains (antigenic shift) [55, 62, 63]. The introduction of new IAV subtypes distinct from previously circulating strains into the human population results in a succession of pandemic waves. Pandemics differ from seasonal IAV in exhibiting a higher transmissibility and a higher rate of mortality, particularly among younger patients who lack immunity to similar historically circulating strains [8-10, 14, 64-69]. For example, the $1918 \mathrm{H} 1 \mathrm{~N} 1$ influenza pandemic originated from an avian IAV and caused an estimated 40 million deaths worldwide $[55,62,64]$. Similar recombination events led to the emergence of the $1957 \mathrm{H} 2 \mathrm{~N} 2$ and $1968 \mathrm{H} 3 \mathrm{~N} 2$ influenza pandemics [70], and multiple re-assortments between avian, swine and human viruses resulted in the 2009 H1N1 pandemic influenza strain $[66,70]$. Since 1997, recurring infections of humans with avain viruses (subtypes H5N1, H7N7, H9N2, H7N2 and H7N9) and high mortality have raised concerns about highly pathogenic avian viruses crossing the species barrier and gaining pandemic potential $[69,71]$.

Careful clinical and pathological studies of patients infected with the 2009 H1N1 virus revealed important insights [14]. While viral replication typically peaked at the time of maximal symptoms and declined thereafter, prolonged detection of virus persisted for days in some patients with mild disease. In patients with respiratory failure, the virus was detected in the upper and lower respiratory tract of some patients weeks after the infection. Autopsy studies revealed that severe infection with influenza damages the airway and alveolar epithelium resulting in diffuse alveolar damage complicated by bacterial pneumonia, most commonly with Streptococcus pneumoniae and Staphylococcus aureus, in a significant minority (26-38\%) of patients [14].

\section{Molecular and cellular interactions at the virus-host interface}

The IAV targets epithelial cells of the upper and lower respiratory tract through the binding of HA to either 2,3- or 2,6-linked sialic acids [4,52, 72, 73]. Seasonal, as well as pandemic, strains show specificity for 2,6-linked sialic acids that are prominently expressed in the human trachea, whereas the avian viruses preferentially bind to the 2,3-linked sialic acids that are expressed in alveolar type II cells $[4,5,74]$. The sialic acid specificity of different viruses has been suggested to explain why some viruses appear to be more lethal than others $[5,73,75]$. 
Attachment to sialic acid residues on airway and alveol epithelium, membrane fusion and viral entry

Matrix protein-1

Polymerase proteins: PB1 $\mathrm{PB} 2$ and PA

\section{Nucleocapsid protei}

Nonstructural protein-1

PB1-F2
Proton selective ion channel required for viral entry, assembly and budding

Structural links between the membrane and ribonucleoprotein core

Enzymatic cleavage of terminal sialic acid residues from newly formed virions and release of progeny

RNA polymerase complex proteins

\section{Packaging of the viral genome}

Immune evasion

Export of viral ribonucleoproteins from the nucleus during viral replication

Induction of host cell apoptosis
Alternate binding to $\alpha-2,3$ or $-2,6$ linked sialic acid contributes to pathogenicity

In the human airway, proteolytic cleavage and disease severity is connected to host proteases TMPRSS2 and HAT [25-27] The addition of $\mathrm{N}$-linked glycosylations mask haemagglutini as an antigenic epitope [28-31] but trigger recognition by C-type lectins [32-34]

After haemagglutinin, neuraminadase is the major antigenic epitope Currently approved therapies for IAV infection losteltamivir, zanamivir, laninamivir and peramivir) target neuraminadas

Matrix protein- 2 has been suggested to promote apoptosis by inhibition of autophagy [35] and induces degradation of $\mathrm{ENaC}$ and CFTR $[36,37]$ and, therefore, impacts alveolar fluid clearance

The polymerase subunits have been connected to viral pathogenicity and interact with $>300$ cellular proteins [38] Mutations can alter replication efficiency; e.g. a single amino acid substitution (E627K) induces higher pathogenicity in the 1918,1957 and 1968 pandemic IAV strains $[39,40]$ and is found in circulating $\mathrm{H} 5 \mathrm{~N} 1$ and $\mathrm{H} 7 \mathrm{~N} 9$ variants

Critical for viral evasion of the host immune response It binds a complex of viral RNA, RIG-1 and TRIM25 to inhibit downstream antiviral signalling $[41,42]$

It also induces the downregulation of the IFN- $\alpha$ receptor [43] and upregulates inhibitors of JAK/STAT signalling ISOCS1 and SOCS3) $[43,44]$

During infection, non-structural protein-1 also blocks pro-apoptotic signalling by protein kinase $R[45,46]$ and prevents the activation of NF- $\mathrm{kB}$ [47]

PB1-F2 increases mitochondrial membrane permeability through interactions with mitochondrial membrane proteins through interactions with mitochondrial membrane proteins
ANT3 and VDAC, to enhance BAK/BAX-mediated cytochrome C release $[48-50]$

The mature virion comprises eight structural proteins; the other three are expressed during viral replication. Haemagglutinin and neuraminidase, required for virus binding and release, respectively, are present in the viral envelope. Together, haemagglutinin and neuraminidase determine the antigenic properties of the virus and are used to define different viral strains, e.g. the H1N1 strain responsible for the 2009 pandemic and the H7N9 strain responsible for a recent outbreak of avian influenza in Asia. Some of the viral proteins represent putative novel targets for antiviral therapy. TMPRSS2: transmembrane protease, serine 2: HAT: human airway trypsin-like protease; ENaC: epithelial sodium channels; CFTR: cystic fibrosis transmembrane conductance regulator; RIG-1: retinoic acid inducible gene-1; IFN: interferon; JAK: janus kinase; STAT: signal transducer and activator of transcription; NF- $\mathrm{KB}$ : nuclear factor- $\mathrm{\kappa B}$; VDAC: voltage-dependent anion channels. "\# not expressed by all viruses. 
The presence of viral RNA in the cytosol activates three major intracellular immune pathways that initiate the innate immune response to the virus: retinoic acid inducible gene-1 (RIG-1) proteins, Toll-like receptors (TLRs; primarily TLR3 and TLR7), and inflammasome (fig. 2a) [76]. Binding of viral RNA to helicase domains on RIG-1 trigger its interaction with mitochondria associated antiviral signalling protein (MAVS), which induce the generation of type I and III interferons (IFN- $\alpha / \beta$ and $-\lambda$ ) and activate the pro-inflammatory transcription factor nuclear factor (NF)- $\kappa \mathrm{B}$ [77]. In addition, viral RNA acts via MAVS in the epithelium and via nucleotide-binding oligomerisation domain-containing protein-like receptor-3 in myeloid cells to activate the inflammasome, leading to the release of IL- $1 \beta$ and IL-18 [76, 78, 79]. IFNs act through receptors widely expressed in myeloid and epithelial cells in the infected lung to increase the transcription and release of hundreds of IFN-regulated genes, while activation of inflammasome and $\mathrm{NF}-\kappa \mathrm{B}$ induce the release of pro-inflammatory cytokines and chemokines [76]. All of these responses promote viral clearance; however, they may also contribute to tissue injury [80-82].

After the infected epithelial cells, tissue-resident alveolar macrophages are the first responders to viral infection in the lung (fig. 2b). They can promote viral clearance through the phagocytosis of collectin-opsonised viral particles or infected apoptotic cells (efferocytosis) and release of a plethora of inflammatory cytokines and chemokines to initiate and drive the immune response [83-86]. In pigs, depletion of resident alveolar macrophages prior to IAV infection resulted in a higher viral load, decreased type I IFN production and increased morbidity and mortality $[87,88]$. As a primary source of type I IFN, resident alveolar macrophages may also stimulate memory $\mathrm{CD} 8^{+} \mathrm{T}$-cells in a $\mathrm{T}$-cell receptor-independent way [89]. Notably, virus-induced killing [90] or site-specific suppression of resident alveolar macrophages may promote disease severity. There is evidence that the antiviral capabilities of tissue resident macrophages can be enhanced; for example, by deletion of CD200R, macrophage receptor with collagenous structure (MARCO) or the ubiquitin-editing protein tumour necrosis factor (TNF)- $\alpha$-induced protein 3 prior to IAV infection, which results in faster viral clearance and a better outcome [91-93].

The release of pro-inflammatory cytokines induces the recruitment of circulating monocytic precursors into the lung and their differentiation into monocyte-derived alveolar macrophages and dendritic cells (DCs), including TNF/inducible nitric oxide synthase (iNOS)-producing DCs. Monocyte-derived alveolar macrophages differ from tissue resident alveolar macrophages in that the former release higher levels of pro-inflammatory cytokines typically associated with classical activation or "M1" polarisation, including TNF- $\alpha$ and iNOS, which promote IAV-related alveolar injury [94-98]. Preventing the recruitment of these macrophages into the lung, for example by deleting CCR2 or its ligand, reduces the severity of IAV infection without affecting viral clearance [99-102]. As a result, therapies that target these macrophages may be of interest. For example, priming of murine lungs with colonising $S$. aureus affects the polarisation of monocyte-derived alveolar macrophages and attenuates IAV infection, suggesting a previously undescribed mechanism by which the airway microbiota may protect against influenza-mediated lethal inflammation [103].

Activation of the intrinsic apoptotic pathway by viral proteins during infection, and the extrinsic apoptotic pathway by inflammatory cytokines, results in apoptosis and sometimes necrosis of the airway and alveolar epithelium, which are well-described features of IAV-induced ARDS (fig. 2c) [104-106]. For example, in response to IAV, the pro-apoptotic cytokine TNF-related apoptosis-inducing ligand (TRAIL) is strongly expressed on monocyte-derived alveolar macrophages in mice and in bronchoalveolar lavage macrophages from patients with pandemic H1N1 influenza-induced ARDS [107]. TRAIL can directly induce alveolar epithelial cell apoptosis by interacting with death receptor 5, which is highly expressed in the lung epithelium at baseline and is upregulated by type I IFNs during viral infection [107, 108]. Strategies that prevent TRAIL-induced apoptosis attenuate the severity of IAV pneumonia in mice without compromising viral load [107, 108], whereas those that promote it worsen injury [109].

DCs are another key component of the innate immune response to IAV infection in the lung [110]. Different subsets of DCs reside in the lung and airways and respond to IAV infection. The $\mathrm{CD}_{103^{+}}$subset of DCs (major histocompatibility complex class $\mathrm{II}^{\text {hi }} \mathrm{CD} 11 \mathrm{c}^{\text {hi }} \mathrm{CD} 103^{+}$) plays a particularly important role. These cells reside in the pulmonary epithelium from where they extend processes into the airway lumen; here, they encounter viral particles or the remnants of virus-infected cells. In the presence of inflammatory cytokines released from the lung epithelium and inflammatory cells, e.g. those produced by inflammasome (IL-1 $\beta$ and IL-18) or granulocyte-macrophage colony-stimulating factor (GM-CSF) [110-113], they are induced to migrate to the draining lymph nodes. In the lymph nodes, $\mathrm{CD}_{103^{+}} \mathrm{DCs}$ serve as potent antigen-presenting cells for the activation of naïve $\mathrm{CD}^{+}$and $\mathrm{CD} 4^{+} \mathrm{T}$-cells and for the presentation of viral antigens to rare virus-specific memory T-cells required for adaptive immunity $[114,115]$.

The expansion of naïve $\mathrm{CD}^{+}$and $\mathrm{CD}^{+}$and virus-specific memory T-cells are key to the adaptive immune responses to IAV infection. Antigen-specific $\mathrm{CD}^{+} \mathrm{T}$-cells induce the lysis of IAV-infected cells via the release of cytotoxic granules upon antigen engagement, and can work with monocyte-derived 
a)

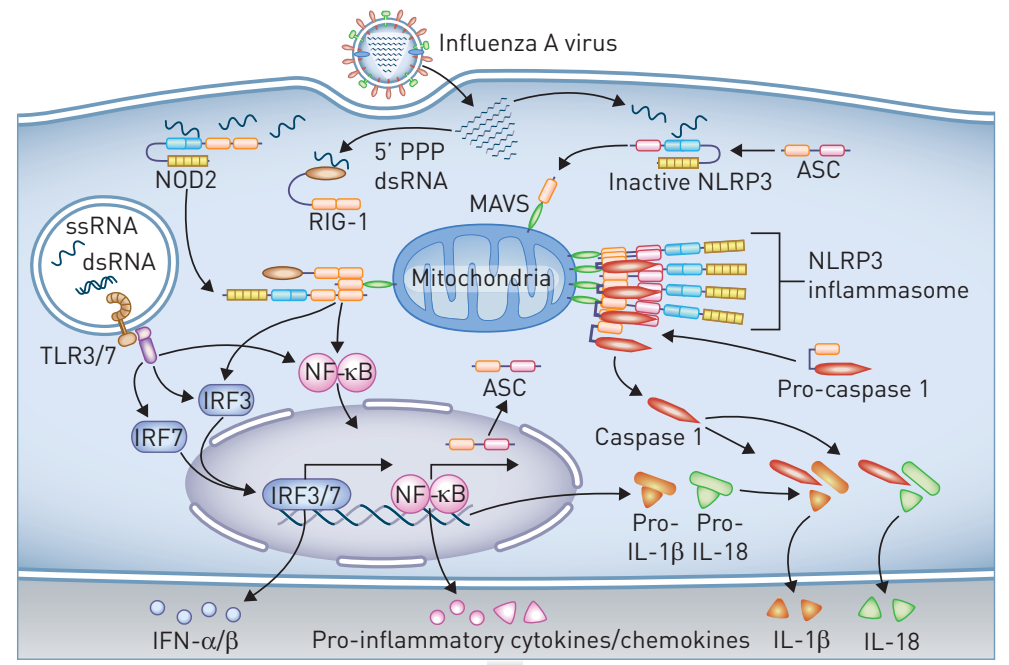

b)

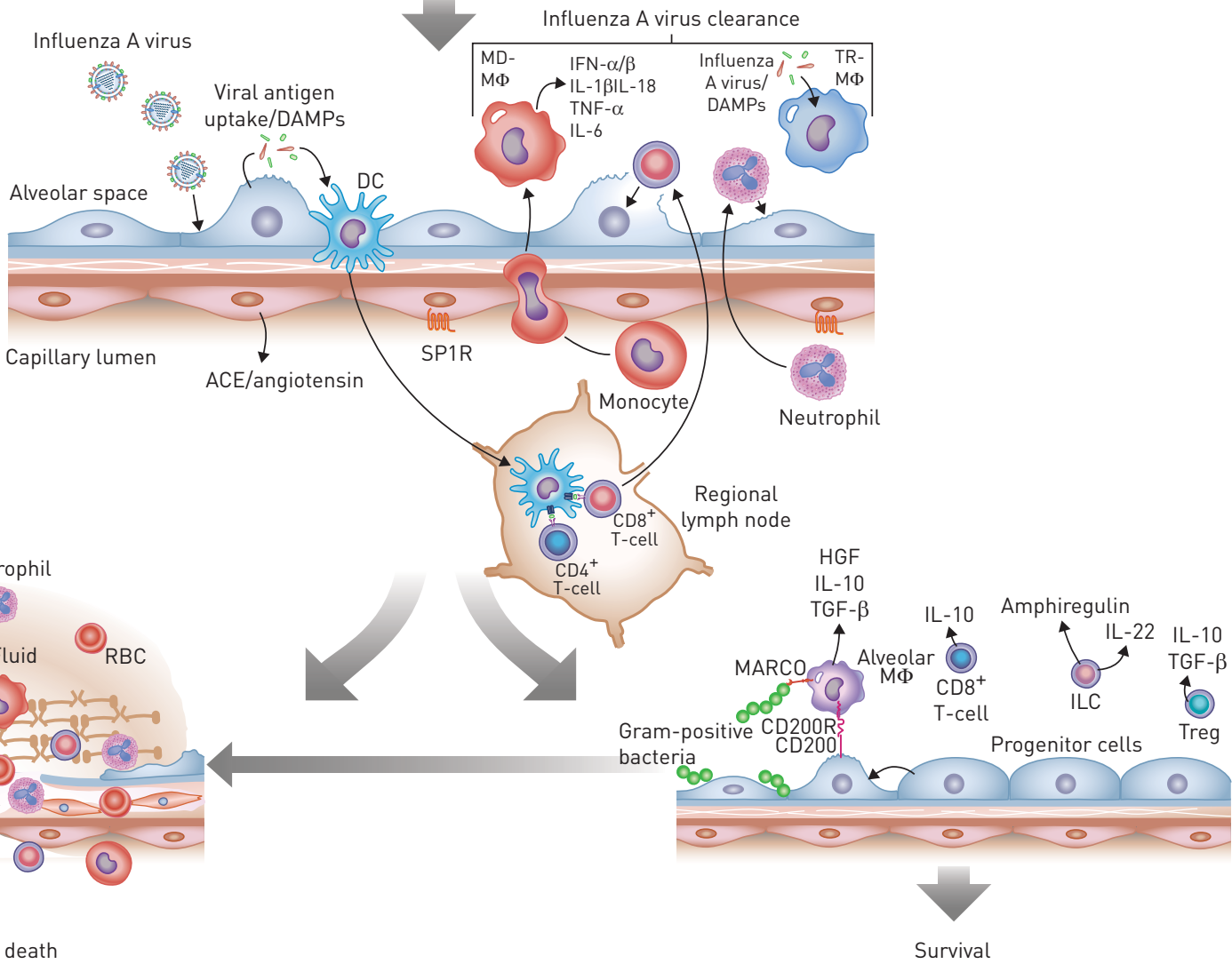

Acute lung injury and death

Survival

FIGURE 2 Influenza infection results in the sequential activation of beneficial and detrimental host-immune pathways in the lung. a) The earliest responses are seen in the infected airway or alveolar epithelial cell (AEC). From left to right, the presence of intracellular viral RNA activates Toll-like receptors (TLRs), primarily TLR7 and TLR3, to induce pathways that culminate in activation of interferon regulatory factor (IRF) 3 or IRF7, which increase the transcription of the type I interferon (IFN)- $\alpha / \beta$. Activation of this pathway can also induce the transcription of pro-inflammatory cytokines and chemokines by activating nuclear-factor (NF)-kB. $5^{\prime}$ triphosphorylated double stranded RNA (5'-PPP dsRNA) released into the cytosol during influenza infection induces a conformational change in retinoic acid-inducible gene-I (RIG-I), which interacts with mitochondrial antiviral signalling protein (MAVS) allowing it to activate nucleotide-binding oligomerisation domain-containing protein (NOD)2. This also induces the transcription of type I IFNs via IRF3 and pro-inflammatory cytokines via NF-кB. The inflammasome proteins ASC (adapter protein apoptosis-associated speck-like protein containing a CARD), pro-interleukin (IL)-1 $\beta$ and pro-IL-18 are induced by NF-KB. In the presence of viral RNA, ASC interacts with NLR family, pyrin domain-containing (NLRP) 3 and MAVS to induce activation of the NLRP3 inflammasome, which cleaves and activates caspase-1 to generate IL-1 $\beta$ and IL-18, thereby amplifying the inflammatory cascade. b) Infection of the airway or alveolar type II cells results in the release of damage-associated molecular pattern molecules (DAMPs) and pathogen-associated molecular pattern molecules (PAMPs), which are sensed by resident dendritic cells (DCs). DCs migrate to regional lymph nodes to activate cytotoxic $\left(\mathrm{CD} 8^{+}\right)$and helper $\left(\mathrm{CD} 4^{+}\right)$T-cells, as well as rare memory T-cells capable of inducing a specific antiviral response (not shown). At the same time, DAMPs, PAMPs, endocytosed viruses and perhaps influenza infection itself induce the release of type I IFNs and inflammatory cytokines from tissue-resident alveolar macrophages (TR-M $\Phi$ ) and DCs (not shown). These cytokines/ chemokines induce the recruitment of neutrophils and the recruitment and differentiation of peripheral blood monocytes into monocyte-derived alveolar macrophages

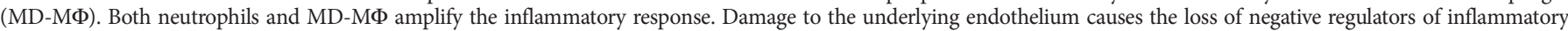
cell recruitment and inflammation, including signalling through the sphingosine-1 phosphate receptor (SP1R) and the release of angiotensin via angiotensin converting enzyme (ACE), thereby amplifying the inflammatory response. c) The resulting release of type I IFNs and inflammatory cytokines and the action of cytotoxic T-cells is critical for viral 
alveolar macrophages to induce cell death via the extrinsic apoptotic pathway by releasing TNF- $\alpha$ or TRAIL $[116,117]$. Activated T-cells also secrete an array of other pro-inflammatory cytokines (e.g. TNF- $\alpha$, CCL3 and CCL5), but the role of these cytokines in viral clearance and/or the induction of lung injury is not clear [118]. Interestingly, a substantial body of evidence suggests that the cytolytic activity and cytokine function of effector T-cells are modified by factors present in the inflammatory milieu of the IAV-infected lung [119-122]. The complexity of these interactions is highlighted by the discovery that hHigh mobility group protein B1 (HMGB1), a damage-associated molecular pattern (DAMP) molecule released from the infected epithelium, promotes the DC-dependent activation of IAV antigen-specific $\mathrm{CD}^{+}$T-effector cells via an interaction with RAGE (receptor for advanced glycation endproducts) [123].

Emerging evidence highlights the importance of the endothelium in organising the immune response to IAV infection. For example, the upregulation of sphingosine- 1 phosphate receptor on endothelial cells is required to orchestrate the ingress and egress of inflammatory cells to the injured lung during infection $[18,124]$. Moreover, the pulmonary endothelium is one of the major sites of angiotensin-converting enzyme (ACE) production. ACE2, a close homologue of ACE, functions as a negative regulator of the angiotensin system and protects against IAV-induced ARDS [125, 126]. Components of the coagulation and fibrinolysis cascades have also been associated with promotion of IAV-induced lung injury [127, 128]. An emerging concept in the field is that host-derived molecular patterns or DAMPs, such as HMGB1 or oxidised phospholipids, drive lung injury via activation of the TLR4 pathway during IAV infection [80, 129]. Finally, the presence of high titres of low-avidity, non-protective antibodies and deposition of immune-complexes together with complement activation in the lung endothelium was associated with the severity of lung injury in patients infected with the 2009 pandemic H1N1 IAV [130].

\section{Viral clearance versus immune-mediated lung injury}

In patients who succumb to IAV infection, post mortem examination of the lung almost always reveals diffuse alveolar disease, but viral RNA is present in only a subset of patients [14]. These results and findings from published studies of IAV infection in animals suggest that mortality in IAV infection might result from an overly exuberant immune response or impaired viral clearance $[76,131]$. An examination of the role of neutrophils in IAV infection provides an illustrative example. Using an elegant systems biology approach, investigators found that excessive activation of inflammatory signalling networks distinguished lethal from sublethal infections in mice, and the transcriptional signature that predicted lethality was largely attributable to neutrophils [131]. Several studies have found that strategies that interrupt CXCL2 or CXCL10 driven feed-forward circuits involving neutrophils reduced lung injury during IAV infection [131-134]. Despite this, the complete depletion of neutrophils prior to IAV infection is associated with failure of viral clearance and worsened lung injury after IAV infection, suggesting that neutrophils play a part in the multicellular co-ordinated response to the virus in the lung [135]. Consistent with these findings, neutropaenia was found to be an independent risk factor for influenza-associated death in a cohort of haematopoietic stem cell transplant recipients [136].

\section{Resolution of lung injury and alveolar regeneration}

The induction of neutralising antibodies to the surface of NA and HA is associated with the clearance of infectious viruses and is necessary for the prevention of re-infection with the same IAV strain [137]. However, even in the absence of cross-reactive neutralising antibodies, $\mathrm{CD} 8^{+} \mathrm{T}$-cells specific to conserved influenza epitopes are probably sufficient to mediate cross protection against severe influenza in humans [138]. Viral clearance is associated with the resolution of acute inflammation (fig. 2c). This process is mediated through a variety of mechanisms, and increasing evidence suggests that different populations of T-cells are centrally involved. $\mathrm{CD}^{+} \mathrm{T}$-cells produce anti-inflammatory IL-10 during IAV infection to attenuate and resolve inflammation [139]. Activated macrophages express the co-stimulatory molecule $\mathrm{CD} 86$, which promotes the expansion of $\mathrm{FOXP}^{+}$regulatory T-cells (Treg) to suppress neutrophil-driven cytokine release [140]. Highlighting the importance of these cells, the adoptive transfer of Tregs into

\footnotetext{
FIGURE 2 (continued.)
}

clearance; however, an overly exuberant inflammatory response can disrupt the alveolar-capillary barrier resulting in alveolar flooding, intra-alveolar fibrin accumulation and the generation of oxidised phospholipids (OxPLs), which can further worsen inflammation as shown in the left-hand panel. In contrast, successful control of viral replication allows the development of specific antiviral humoral and cell-mediated immunity (not shown). Successful control of both viral replication and the resulting immune response allows for alveolar repair (right-hand panel). The denuded alveolar epithelium is reconstituted through the proliferation of regional progenitor cells driven by signals from the tissue microenvironment. Innate lymphoid cells (ILC) release the anti-inflammatory cytokine IL-22 and the growth factor/mitogen amphiregulin. Alveolar macrophages become "M2" polarised and express scavenging and anti-inflammatory surface proteins, including macrophage factor with collagenase structure (MARCO) and CD200R, and release growth factors and anti-inflammatory cytokines including hepatocyte growth factor (HGF), transforming growth factor (TGF)- $\beta$ and IL-10. These anti-inflammatory reparative signals temporarily impair local innate immune responses, increasing the susceptibility to Gram-positive bacterial superinfection. ssRNA: single-stranded RNA; dsRNA: double-stranded RNA; TNF: tumour necrosis factor; RBC: red blood cells; TRAIL: TNF-related apoptosis-inducing ligand; Treg: regulatory T-cell. 
immunodeficient mice controlled the otherwise lethal inflammation mediated by innate immune cells during IAV infection [141]. The type I IFNs can inhibit the activation of T-helper 17 responses and reduce the recruitment of neutrophils to the lung. IFN- $\gamma$ released from activated T-cells inhibits the expression of the scavenger receptor MARCO on alveolar macrophages [142]. While all of these processes limit the immune response, they come at the expense of an enhanced susceptibility to secondary bacterial infection, particularly with Gram-positive organisms. Indeed, retrospective examination of autopsy specimens from the 1918 and 2009 pandemics suggests that a substantial fraction of patients died from bacterial infections after successful clearance of the virus [14, 143].

Influenza virus infection results in large areas of denuded basement membranes in the upper and lower airways, loss of the delicate microarchitecture of the lung and formation of micro- and macroatelectasis. Therefore, a robust regeneration response is required to restore gas exchange and protect from secondary microbial infection, which must include the termination of inflammation, matrix deposition, progenitor cell proliferation and re-establishment of the alveolar-capillary barrier. A number of studies have recently highlighted the importance of innate lymphoid cells in the maintenance and regeneration of mucosal surfaces. Lymphoid tissue inducer cells, which are involved in development of lymphoid tissues, and innate lymphoid cells secrete IL-22, a tissue-protective cytokine that induces the expression of genes that are important for lung regeneration after IAV infection [144-147]. In addition, IL-22 stimulates pulmonary epithelial cells to increase antibacterial genes, such as lipocalin 2, which may be important for protection from secondary bacterial pneumonia $[145,148]$ and increases the expression of genes encoding anti-apoptotic proteins including B-cell lymphoma (Bcl)2 and Bcl-2l1 [149]. Innate lymphoid cells are also required for the release of IL-33, which induces the secretion of amphiregulin, a member of the epidermal growth factor (EGF) family that is essential for maintenance of epithelial integrity and proper airway remodelling [150]. Of note, the administration of recombinant amphiregulin to mice co-infected with IAV and bacteria significantly improved lung epithelial regeneration and survival [151]. Finally, Treg were found to directly drive epithelial progenitor cell proliferation following endotoxin-induced lung injury to promote lung repair; however, it is not known whether they play a similar role after IAV infection [152]. These discoveries are important as they may suggest therapies that can facilitate tissue regeneration in patients with severe IAV-induced lung injury after viral clearance is achieved.

M2-polarised macrophages have been associated with tissue repair of the acutely inflamed lung [153]; however, experimental evidence of a similar role in respiratory viral disease is limited. Monocyte-derived alveolar macrophages were found to secrete hepatocyte growth factor (HGF), a potent lung epithelial cell mitogen, which induced proliferation of type II alveolar epithelial cells in a mouse IAV infection model $[154,155]$. Tissue resident alveolar macrophages promote the regeneration of type II alveolar epithelial cells after endotoxin-induced lung injury via a pathway that requires TNF- $\alpha$ and GM-CSF, another proliferative and anti-apoptotic factor for the lung epithelium [156, 157]. There is evidence this same pathway is active during the resolution of IAV infection [113].

The mechanisms by which the extensively damaged airway and alveolar epithelium are repaired following IAV infection are not completely understood. Replacement of damaged or denuded areas of epithelium is accomplished by the proliferation of one or more airway and alveolar progenitor cells; partially differentiated cells within the airways or epithelial space capable of self-renewal and differentiation in response to environmental cues provided by the surrounding mesenchyme [20]. These include populations of airway basal cells expressing p63 and keratin 5 , subsets of club cells in the distal airways including itgb $4^{+} \mathrm{CD} 24^{\text {low }}$ cells, and putative populations of bronchoalveolar stem cells at the bronchoalveolar duct junction. Within the alveoli, itgb $4^{+}$cells, "bipotent" type I and type II alveolar epithelial cell progenitors and alveolar type II cells have been attributed stem/progenitor cell functions during repair [158, 159]. While all of these populations have been reported to expand in different models of lung injury, the emergence of p63-positive and keratin 5-positive epithelial pods in the alveolar space has only been observed after severe IAV-induced lung injury $[160,161]$. Whether this is accompanied by expansion of other progenitor pools or whether direct or immune-mediated damage to the more distal progenitor populations in response to viral infection necessitates the expansion of the airway stem cell pool is not known. Soluble growth factors involved in these responses comprise, among others, fibroblast growth factors, EGFs, HGFs, and transforming growth factor- $\beta$ [158], some of which are induced in IAV infection [150,154, 162, 163]. Our own data reveal that a itgb4 ${ }^{+}$ progenitor cell population is crucial for bronchial and alveolar repair after IAV-induced lung injury in mice, a process involving cross-talk with resident mesenchymal niche cells, extracellular matrix laminins and FGF10 (S. Herold and G.R.S. Budinger; unpublished observation).

\section{Therapy}

For patients who present with $<4$ days of fever, myalgia, headache, fatigue, dry cough, sore throat and rhinorrhoea during the influenza season, and in patients who require hospitalisation for respiratory symptoms 
during the influenza season, the use of rapid diagnostic tests may help to guide therapy $[14,164]$. The most common is the rapid influenza diagnostic test, an immunoassay that identifies the presence of influenza A or B viral nucleoprotein antigens in respiratory specimens. Rapid influenza diagnostic tests yield results in $\sim 15$ min but have limited sensitivity and specificity. Rapid reverse-transcription PCR tests for IAV or influenza B virus RNA are conducted on nasopharyngeal swabs or other respiratory samples, distinguish between different influenza strains and are highly specific (>90\%), but relatively insensitive (40-70\%) [14]. Viral cultures can be considered in patients in whom diagnostic uncertainty requires additional testing or when novel strains of influenza are suspected. Treatment with NA inhibitors is recommended as early as possible after symptom onset for patients: with confirmed or suspected IAV who present within $48 \mathrm{~h}$ of symptom onset; in high-risk or hospitalised patients, including children aged $<2$ years and adults $>65$ years; patients with chronic illness, immunosuppression, pregnancy; and nursing home residents $[14,58]$. Treatment of severe IAV with ARDS includes the use of higher dose, intravenous NA inhibitors and aggressive supportive care. Several groups have reported favourable clinical outcomes using extracorporeal membrane oxygenation to support patients with severe hypoxaemic respiratory failure secondary to IAV [165].

\section{At-risk populations}

Seasonal IAV infection causes disproportionate mortality in the elderly. For example, compared with 1849 year olds, the incidence of respiratory failure induced by IAV infection is lower in children but 20 times higher in patients aged 65-74 years [15]. In contrast, pandemic IAV often causes disproportionate mortality in younger individuals $[8,9,14,65,69]$. This is thought to result from partial immunity conferred by exposure to historically circulating strains in older individuals. During the pandemic caused by the 2009 H1N1 virus, severe prolonged exacerbations of asthma or chronic obstructive pulmonary disease were reported in $14-15 \%$ of patients and, in one study, $29 \%$ of children and $27 \%$ of adults hospitalised with IAV had a prior diagnosis of asthma $[9,14]$. Post hoc analysis of data collected during the 2009 H1N1 influenza pandemic also suggested that obesity was an independent risk factor for the development of respiratory failure and mortality $[10,166,167]$. Pregnancy is another risk factor for poor outcomes, with the highest risk in the third trimester. In the pandemics of 1918, 1957 and 2009, pregnancy was associated with a risk of respiratory failure and death approximately five times higher than the population as a whole, and pregnancy is also a risk factor for poor outcomes after seasonal IAV infection [168]. It is not known whether this is as a result of changes to the immune system or cardiovascular and pulmonary changes during pregnancy that increase the likelihood of acute lung injury. Patients with immunosuppression were reported to exhibit prolonged viral shedding and were at increased risk for poor clinical outcomes during the $2009 \mathrm{H} 1 \mathrm{~N} 1$ influenza pandemic [14]. Patients hospitalised due to H1N1 viral infection during this pandemic showed enrichment for a minor IFITM3 (interferon-inducible transmembrane protein 3) allele due to a single-nucleotide polymorphism that alters IFITM3 protein function, highlighting that genetic susceptibility may account for severe IAV-associated disease [169].

\section{Novel therapeutic strategies}

M2 channel inhibitors (rimantadine and amantadine) are no longer recommended for the treatment of influenza due to the widespread emergence of resistance ( $>99 \%$ of strains) and their lack of efficacy against influenza B. This leaves NA inhibitors (zanamivir, oseltamivir, laninamivir and peramivir) as the only currently recommended therapies for IAV infection [57, 170, 171]. Unfortunately, reports of viral resistance to oseltamivir have rapidly increased during recent years $[172,173]$. While some investigators have questioned the clinical benefit of oseltamivir for uncomplicated IAV and influenza B virus infection $[174,175]$, most studies suggest improved clinical outcomes in severely ill patients, even when therapy is administered relatively late in the infection $[59,60]$, and higher dose parenteral therapy is recommended for the treatment of patients with severe IAV or influenza B virus infection [176].

The viral replication machinery is an attractive target for the development of influenza-specific antivirals. Screening of large compound libraries identified several small molecules that target components of the viral polymerase complex [177]. Favipiravir (T-705; www.clinicaltrials.gov identifier NCT01068912), a nucleoside inhibitor that efficiently blocks the RNA synthesis activity of PB1, is probably the most advanced compound to date and is currently in phase III trials [178, 179]. Another small molecule, DAS181, is a sialidase-fusion protein which, when administered by inhalation, cleaves sialic acids on the lung epithelium rendering them inaccessible to infection by virus. DAS181 was effective in reducing viral loads in a murine model and in a phase II clinical trial $[180,181]$. Clinical trials of AVI-7100, a phosphorodiamidate morpholino oligomer that is designed to interfere with expression of the M1 and M2 genes (www.clinicaltrials.gov identifier NCT01747148), and flufirvitide, a peptide inhibitor binding to HA and inhibiting fusion (www.clinicaltrials.gov identifier NCT01990846), are currently underway (table 1).

A number of agents with potential immunomodulating effects, including immunoglobulins, $N$-acetylcysteine, macrolides, peroxisome proliferator-activated receptors agonists, celecoxib and mesalazine, have been 
suggested for clinical use [182], but only a few of them reached clinical trials. Statins were shown to modulate host immunity by their immunomodulatory and anti-inflammatory functions and were first suggested as a potential therapeutic strategy to reduce IAV-induced inflammation in 2005 [183]. However, rosuvastatin treatment did not improve outcomes after IAV infection in a murine model and a recent multicentre trial of statins for the treatment of patients with ARDS secondary to sepsis produced negative results $[184,185]$.

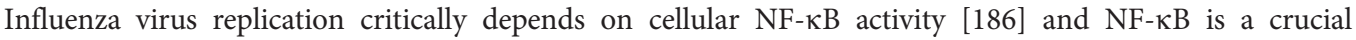
pro-inflammatory signalling module, suggesting that strategies to inhibit the NF- $\kappa \mathrm{B}$ pathway may be suitable for intervention. Intratracheal application of the NF- $\kappa \mathrm{B}$ inhibitor acetylsalicylic acid into lethally infected mice significantly improved survival, both because of its antiviral and additional anti-inflammatory effects [187]. On the basis of these data, an acetylsalicylic acid-derived NF- $\kappa$ B inhibiting compound is now being used in a phase II clinical trial for severe influenza (www.clinicaltrialsregister.eu/ ctr-search/trial/2012-004072-19/DE). In a related approach, small molecule inhibitors of the cellular Raf/ MEK/ERK cascade, which is known to efficiently support viral replication and mediate pro-inflammatory events, confer strong antiviral effects in IAV-infected mice, and are being evaluated in phase I to phase III clinical trials for other indications [186, 188]. Finally, GM-CSF, an important mediator of the antiviral host defence and a factor promoting repair of the alveolar epithelium [113, 156], has been administered via inhalation to patients with moderate-to-severe pneumonia-associated ARDS (including patients with IAV infection), yielding results supportive of a future clinical trial [189].

\section{Vaccination}

Vaccination with IAV/influenza B virus vaccines is key to limiting the public health impact of influenza. The influenza vaccine is updated yearly by investigators at the World Health Organization who work with their collaborative partners in the USA and Europe to identify variants of prevalent viruses in the human population considered most likely to cause infections in the following season [190]. Most vaccines are inactivated influenza vaccines, which contain three (trivalent) or four (quadrivalent) antigens of two IAV and one or both influenza B viral strains and are administered intramuscularly; a live attenuated trivalent vaccine is approved for children and is administered intranasally [191]. Widespread adoption of the quadrivalent vaccine is likely in the future. While specific recommendations vary by country, most agencies recommend influenza vaccination for a large majority $(\geqslant 85 \%)$ of the population, particularly for women who are or are planning on becoming pregnant. For example, the Centers for Disease Control and Prevention in the USA recommends vaccinations for all individuals aged $>6$ months. In infants aged $<6$ months, for whom vaccination is not approved, protection is conferred by vaccination of their mothers $[191,192]$. The morbidity associated with influenza is probably further reduced by the administration of pneumococcal vaccine to all children aged $<5$ years, older individuals ( $>65$ years of age) and younger individuals with immunocompromising conditions [191].

\section{Research challenges}

The success of current vaccination programmes and the array of novel therapies on the horizon highlight both the success of previous research and the need for more research into the pathophysiology of influenza infection, however, significant challenges remain. Research investigating the genetic basis of influenza virulence has generated vigorous public debate in which the scientific community has argued that the public health benefits of widespread dissemination of information for progress in diagnostics, vaccines and therapies outweigh perceived concerns for bioterrorism [193]. Because humans (and for some strains of pigs and birds) are the only natural hosts for IAV, the use of mouse models for research represents another important challenge. While they cannot fully recapitulate the human disease, murine models have allowed investigators to use genetic strategies to elucidate pathways critical for the response to IAV in vivo, many of which have been described previously [76]. Improvements to these models, for example by using mice with fully humanised immune systems, may assist with the translation of findings to the clinic [194]. Finally, the time between research discoveries in the laboratory and the development of therapies remains fixed at 15-20 years [195]. To combat a rapidly evolving pathogen like IAV, we need to find faster mechanisms to bring recently discovered strategies, including many of those described in this review, to the care of patients.

\section{Conclusions}

It is increasingly evident that the outcome of IAV-associated lung injury is determined by both viral and host factors, suggesting an optimal range of activity for the immune response to viral infection. An enhanced understanding of the pathobiology of IAV infection suggests that novel therapies targeting the host in combination with conventional antiviral therapies may be beneficial. Such therapeutic strategies could interfere with host signalling pathways necessary for viral replication, inhibit exaggerated inflammation, or 
promote tissue regeneration in an effort to dampen organ dysfunction and injury [196]. Strategies that limit immune responses, for example, by inhibiting the activation of TLR4 by oxidised phospholipids [80, 197], targeting the S1P receptor or the angiotensin/ACE system $[124,126,197,198]$ or even attenuating the production of type I IFNs [107], have been shown to reduce the severity of IAV-induced mortality in murine models. Similarly, strategies that promote immune resolution or tissue regeneration, e.g. inhibitors of T-cell co-stimulators, resolvins, lipoxins, inhibitors of the CD200 receptor and immunomodulatory antibiotics or glitazones [93, 99, 199-201] may accelerate regeneration in patients with severe disease. Further research is needed to identify cells and pathways that can be specifically targeted over the course of the infection and to develop clinically useful biomarkers that can identify the subset of patients in whom these targeted therapies will be most effective.

\section{Acknowledgements}

The authors would like to thank Jacqueline Schaffer for creating the figures.

\section{References}

1 Centers for Disease Control and Prevention (CDC). Estimates of deaths associated with seasonal influenza United States, 1976-2007. MMWR Morb Mortal Wkly Rep 2010; 59: 1057-1062.

2 Shrestha SS, Swerdlow DL, Borse RH, et al. Estimating the burden of 2009 pandemic influenza A (H1N1) in the United States (April 2009-April 2010). Clin Infect Dis 2011; 52: Suppl. 1, S75-S82.

3 Shinya K, Ebina M, Yamada S, et al. Avian flu: influenza virus receptors in the human airway. Nature 2006; 440: 435-436.

4 van Riel D, den Bakker MA, Leijten LM, et al. Seasonal and pandemic human influenza viruses attach better to human upper respiratory tract epithelium than avian influenza viruses. Am J Pathol 2010; 176: 1614-1618.

5 van Riel D, Munster VJ, de Wit E, et al. Human and avian influenza viruses target different cells in the lower respiratory tract of humans and other mammals. Am J Pathol 2007; 171: 1215-1223.

6 Tumpey TM, Maines TR, Van Hoeven N, et al. A two-amino acid change in the hemagglutinin of the 1918 influenza virus abolishes transmission. Science 2007; 315: 655-659.

7 Yang Z-Y, Wei CJ, Kong WP, et al. Immunization by avian H5 influenza hemagglutinin mutants with altered receptor binding specificity. Science 2007; 317: 825-828.

8 Cao B, Li XW, Mao Y, et al. Clinical features of the initial cases of 2009 pandemic influenza A (H1N1) virus infection in China. N Engl J Med 2009; 361: 2507-2517.

9 Jain S, Kamimoto L, Bramley AM, et al. Hospitalized patients with 2009 H1N1 influenza in the United States, April-June 2009. N Engl J Med 2009; 361: 1935-1944.

10 Estenssoro E, Ríos FG, Apezteguía C, et al. Pandemic 2009 Influenza A in Argentina: a study of 337 patients on mechanical ventilation. Am J Respir Crit Care Med 2010; 182: 41-48.

11 Riscili BP, Anderson TB, Prescott HC, et al. An assessment of h1n1 influenza-associated acute respiratory distress syndrome severity after adjustment for treatment characteristics. PLoS One 2011; 6: e18166.

12 Kuiken T, Taubenberger J. Pathology of human influenza revisited. Vaccine 2008; 26: D59-D66.

13 Short KR, Kroeze EJ, Fouchier RA, et al. Pathogenesis of influenza-induced acute respiratory distress syndrome. Lancet Infect Dis 2014; 14: 57-69.

14 Bautista E, Chotpitayasunondh T, Gao Z, et al. Clinical aspects of pandemic 2009 influenza A (H1N1) virus infection. N Engl J Med 2010; 362: 1708-1719.

15 Ortiz JR, Neuzil KM, Rue TC, et al. Population-based incidence estimates of influenza-associated respiratory failure hospitalizations, 2003 to 2009. Am J Respir Crit Care Med 2013; 188: 710-715.

16 Zhang W, Shi Y, Qi J, et al. Molecular basis of the receptor binding specificity switch of the hemagglutinins from both the 1918 and 2009 pandemic influenza A viruses by a D225G substitution. J Virol 2013; 87: 5949-5958.

17 Rossman JS, Lamb RA. Influenza virus assembly and budding. Virology 2011; 411: 229-236.

18 Teijaro JR, Walsh KB, Rice S, et al. Mapping the innate signaling cascade essential for cytokine storm during influenza virus infection. Proc Natl Acad Sci USA 2014; 111: 3799-3804.

19 Braciale TJ, Sun J, Kim TS. Regulating the adaptive immune response to respiratory virus infection. Nat Rev Immunol 2012; 12: 295-305.

20 Hogan BL, Barkauskas CE, Chapman HA, et al. Repair and regeneration of the respiratory system: complexity, plasticity, and mechanisms of lung stem cell function. Cell Stem Cell 2014; 15: 123-138.

21 Shahangian A, Chow EK, Tian X, et al. Type I IFNs mediate development of postinfluenza bacterial pneumonia in mice. J Clin Invest 2009; 119: 1910-1920.

22 Sun J, Braciale TJ. Role of T cell immunity in recovery from influenza virus infection. Curr Opin Virol 2013; 3: 425-429.

23 Rota PA, Wallis TR, Harmon MW, et al. Cocirculation of two distinct evolutionary lineages of influenza type B virus since 1983. Virology 1990; 175: 59-68.

24 Paul Glezen W, Schmier JK, Kuehn CM, et al. The burden of influenza B: a structured literature review. Am J Public Health 2013; 103: e43-e51.

25 Böttcher E, Matrosovich T, Beyerle M, et al. Proteolytic activation of influenza viruses by serine proteases TMPRSS2 and HAT from human airway epithelium. J Virol 2006; 80: 9896-9898.

26 Hatesuer B, Bertram S, Mehnert N, et al. Tmprss2 is essential for influenza H1N1 virus pathogenesis in mice. PLoS Pathogens 2013; 9: e1003774.

27 Tarnow C, Engels G, Arendt A, et al. TMPRSS2 is a host factor that is essential for pneumotropism and pathogenicity of H7N9 influenza A virus in mice. J Virol 2014; 88: 4744-4751.

28 Blackburne BP, Hay AJ, Goldstein RA. Changing selective pressure during antigenic changes in human influenza H3. PLoS Pathog 2008; 4: e1000058.

29 Abe Y, Takashita E, Sugawara K, et al. Effect of the addition of oligosaccharides on the biological activities and antigenicity of influenza A/H3N2 virus hemagglutinin. J Virol 2004; 78: 9605-9611. 

hemagglutinin. Virology 2008; 376: 323-329.

31 Sun S, et al. Glycosylation site alteration in the evolution of influenza A (H1N1) viruses. PLoS One 2011; 6: e22844.

32 Reading PC, Tate MD, Pickett DL, et al. Glycosylation as a target for recognition of influenza viruses by the innate immune system. Adv Exp Med Biol 2007; 598: 279-292.

33 Tate MD, Brooks AG, Reading PC. Specific sites of N-linked glycosylation on the hemagglutinin of H1N1 subtype influenza A virus determine sensitivity to inhibitors of the innate immune system and virulence in mice. J Immunol 2011; 187: 1884-1894.

34 Vigerust DJ, Ulett B, Boyd KL, et al. N-linked glycosylation attenuates H3N2 influenza viruses. J Virol 2007; 81: 8593-8600.

35 Gannage M, Dormann D, Albrecht R, et al. Matrix protein 2 of influenza A virus blocks autophagosome fusion with lysosomes. Cell Host Microbe 2009; 6: 367-380.

36 Lazrak A, Iles KE, Liu G, et al. Influenza virus M2 protein inhibits epithelial sodium channels by increasing reactive oxygen species. FASEB J 2009; 23: 3829-3842.

37 Londino JD, Lazrak A, Jurkuvenaite A, et al. Influenza matrix protein 2 alters CFTR expression and function through its ion channel activity. Am J Physiol Lung Cell Mol Physiol 2013; 304: L582-L592.

38 Bradel-Tretheway BG, Mattiacio JL, Krasnoselsky A, et al. Comprehensive proteomic analysis of influenza virus polymerase complex reveals a novel association with mitochondrial proteins and RNA polymerase accessory factors. J Virol 2011; 85: 8569-8581.

39 Scholtissek C, Rohde W, Von Hoyningen V, et al. On the origin of the human influenza virus subtypes H2N2 and H3N2. Virology 1978; 87: 13-20.

40 Taubenberger JK, Reid AH, Lourens RM, et al. Characterization of the 1918 influenza virus polymerase genes. Nature 2005; 437: 889-893.

41 Gack MU, Albrecht RA, Urano T, et al. Influenza A virus NS1 targets the ubiquitin ligase TRIM25 to evade recognition by the host viral RNA sensor RIG-I. Cell Host Microbe 2009; 5: 439-449.

42 Rajsbaum R, Albrecht RA, Wang MK, et al. Species-specific inhibition of RIG-I ubiquitination and IFN induction by the influenza A virus NS1 protein. PLoS Pathog 2012; 8: e1003059.

43 Jia D, Rahbar R, Chan RW, et al. Influenza virus non-structural protein 1 (NS1) disrupts interferon signaling. PLoS One 2010; 5: e13927.

44 Pauli EK, Schmolke M, Wolff T, et al. Influenza A virus inhibits type I IFN signaling via NF- $\kappa \mathrm{B}-\mathrm{dependent}$ induction of SOCS-3 expression. PLoS Pathog 2008; 4: e1000196.

45 Li S, Min JY, Krug, RM, et al. Binding of the influenza A virus NS1 protein to PKR mediates the inhibition of its activation by either PACT or double-stranded RNA. Virology 2006; 349: 13-21.

46 Bergmann M, Garcia-Sastre A, Carnero, E, et al. Influenza virus NS1 protein counteracts PKR-mediated inhibition of replication. J Virol 2000; 74: 6203-6206.

47 Wang X, Li M, Zheng H, et al. Influenza A virus NS1 protein prevents activation of NF- $\kappa \mathrm{B}$ and induction of $\alpha / \beta$ interferon. J Virol 2000; 74: 11566-11573.

48 McAuley JL, Chipuk JE, Boyd KL, et al. PB1-F2 proteins from H5N1 and 20 century pandemic influenza viruses cause immunopathology. PLoS Pathog 2010; 6: e1001014.

49 Yoshizumi T, IchinoheT, Sasaki O, et al. Influenza A virus protein PB1-F2 translocates into mitochondria via Tom40 channels and impairs innate immunity. Nat Commun 2014; 5: 4713.

50 Zamarin D, Garcia-Sastre A, Xiao X, et al. Influenza virus PB1-F2 protein induces cell death through mitochondrial ANT3 and VDAC1. PLoS Pathog 2005; 1: e4.

51 Maines TR, Jayaraman A, Belser JA, et al. Transmission and pathogenesis of swine-origin 2009 A(H1N1) influenza viruses in ferrets and mice. Science 2009; 325: 484-487.

52 Kobasa D, Takada A, Shinya K, et al. Enhanced virulence of influenza A viruses with the haemagglutinin of the 1918 pandemic virus. Nature 2004; 431: 703-707.

53 Tate MD, Job ER, Deng YM, et al. Playing hide and seek: how glycosylation of the influenza virus hemagglutinin can modulate the immune response to infection. Viruses 2014; 6: 1294-1316.

54 Uhlendorff J, Matrosovich T, Klenk HD, et al. Functional significance of the hemadsorption activity of influenza virus neuraminidase and its alteration in pandemic viruses. Arch Virol 2009; 154: 945-957.

55 Worobey M, Han G-Z, Rambaut A. A synchronized global sweep of the internal genes of modern avian influenza virus. Nature 2014; 508: 254-257.

56 Rust MJ, Lakadamyali M, Zhang F, et al. Assembly of endocytic machinery around individual influenza viruses during viral entry. Nat Struct Mol Biol 2004; 11: 567-573.

57 Pinto LH, Lamb RA. The M2 proton channels of influenza A and B viruses. J Biol Chem 2006; 281: 8997-9000.

58 Fiore AE, Fry A, Shay D, et al. Antiviral agents for the treatment and chemoprophylaxis of influenza recommendations of the Advisory Committee on Immunization Practices (ACIP). MMWR Recomm Rep 2011; 60: $1-24$.

59 Santesso N, Hsu J, Mustafa R, et al. Antivirals for influenza: a summary of a systematic review and meta-analysis of observational studies. Influenza Other Respir Viruses 2013; 7: Suppl. 2, 76-81.

60 Moscona A. Neuraminidase inhibitors for Influenza. N Engl J Med 2005; 353: 1363-1373.

61 Russell CA, Jones TC, Barr IG, et al. The global circulation of seasonal influenza A (H3N2) viruses. Science 2008; 320: $340-346$

62 Rambaut A, Pybus O, Nelson M. The genomic and epidemiological dynamics of human influenza A virus. Nature 2008; 453: 615-619.

63 Bedford T, Cobey S, Beerli P, et al. Global migration dynamics underlie evolution and persistence of human influenza A (H3N2). PLoS Pathog 2010; 6: e1000918.

64 Taubenberger J. The origin and virulence of the 1918 "Spanish" influenza virus. Proc Am Philos Soc 2006; 150: 1-23.

65 Miller M, Viboud C. The signature features of influenza pandemics - implications for policy. $N$ Engl J Med 2009; 360: 2595-2598.

66 Belshe RB. Implications of the emergence of a novel H1 influenza virus. N Engl J Med 2009; 360: 2667-2668.

67 Cox NJ, Subbarao K. Global epidemiology of influenza: past and present. Annu Rev Med 2000; 51: 407-421. 
69 Li Q, Zhou L, Zhou M, et al. Epidemiology of human infections with avian influenza A(H7N9) virus in China. N Engl J Med 2014; 370: 520-532.

70 Kawaoka Y, Krauss S, Webster RG. Avian-to-human transmission of the PB1 gene of influenza A viruses in the 1957 and 1968 pandemics. J Virol 1989; 63: 4603-4608.

71 Gao R, Cao B, Hu Y, et al. Human infection with a novel avian-origin influenza A (H7N9) virus. N Engl J Med 2013; 368: 1888-1897.

72 Chutinimitkul S, Herfst S, Steel J, et al. Virulence-associated substitution D222G in the hemagglutinin of 2009 pandemic influenza $\mathrm{A}(\mathrm{H} 1 \mathrm{~N} 1)$ virus affects receptor binding. J Virol 2010; 84: 11802-11813.

73 Liu Y, Childs RA, Matrosovich T, et al. Altered receptor specificity and cell tropism of D222G hemagglutinin mutants isolated from fatal cases of pandemic A(H1N1) 2009 influenza virus. J Virol 2010; 84: 12069-12074.

74 Shinya K, Ebina M, Yamada S, et al. Avian flu: influenza virus receptors in the human airway. Nature 2006; 440 435-436.

75 Childs RA, Palma AS, Wharton S, et al. Receptor-binding specificity of pandemic influenza A (H1N1) 2009 virus determined by carbohydrate microarray. Nat Biotechnol 2009; 27: 797-799.

Iwasaki A, Pillai PS. Innate immunity to influenza virus infection. Nat Rev Immunol 2014; 14: 315-328.

Durbin RK, Kotenko SV, Durbin JE. Interferon induction and function at the mucosal surface. Immunol Rev 2013; 255: 25-39.

78 Pothlichet J, Meunier I, Davis BK, et al. Type I IFN triggers RIG-I/TLR3/NLRP3-dependent inflammasome activation in influenza A virus infected cells. PLoS Pathog 2013; 9: e1003256.

79 Ichinohe T, Yamazaki T, Koshiba T, et al. Mitochondrial protein mitofusin 2 is required for NLRP3 inflammasome activation after RNA virus infection. Proc Natl Acad Sci USA 2013; 110: 17963-17968.

80 Imai Y, Kuba K, Neely GG, et al. Identification of oxidative stress and Toll-like receptor 4 signaling as a key pathway of acute lung injury. Cell 2008; 133: 235-249.

81 Davidson S, Crotta S, McCabe TM, et al. Pathogenic potential of interferon $\alpha \beta$ in acute influenza infection. Nat Commun 2014; 5: 3864.

82 Thomas PG, Dash P, Aldridge JR, et al. The intracellular sensor NLRP3 mediates key innate and healing responses to influenza A virus via the regulation of caspase-1. Immunity 2009; 30: 566-575.

83 Wang J, Nikrad MP, Travanty EA, et al. Innate immune response of human alveolar macrophages during influenza A infection. PLoS One 2012; 7: e29879.

84 Kumagai Y, Takeuchi O, Kato $\mathrm{H}$, et al. Alveolar macrophages are the primary interferon-alpha producer in pulmonary infection with RNA viruses. Immunity 2007; 27: 240-252.

85 Hillaire ML, Haagsman HP, Osterhaus AD, et al. Pulmonary surfactant protein D in first-line innate defence against influenza A virus infections. J Innate Immun 2013; 5: 197-208.

86 Hashimoto Y, Moki T, Takizawa T, et al. Evidence for phagocytosis of influenza virus-infected, apoptotic cells by neutrophils and macrophages in mice. I Immunol 2007; 178: 2448-2457.

87 Tumpey TM, García-Sastre A, Taubenberger JK, et al. Pathogenicity of influenza viruses with genes from the 1918 pandemic virus: functional roles of alveolar macrophages and neutrophils in limiting virus replication and mortality in mice. J Virol 2005; 79: 14933-14944.

88 Kim HM, Lee YW, Lee KJ, et al. Alveolar macrophages are indispensable for controlling influenza viruses in lungs of pigs. J Virol 2008; 82: 4265-4274.

89 Kohlmeier JE, Cookenham T, Roberts AD, et al. Type I interferons regulate cytolytic activity of memory CD8 ${ }^{+} \mathrm{T}$ cells in the lung airways during respiratory virus challenge. Immunity 2010; 33: 96-105.

90 Ghoneim HE, Thomas PG, McCullers JA. Depletion of alveolar macrophages during influenza infection facilitates bacterial superinfections. J Immunol 2013; 191: 1250-1259.

91 Ghosh S, Gregory D, Smith A, et al. MARCO regulates early inflammatory responses against influenza: a useful macrophage function with adverse outcome. Am J Respir Cell Mol Biol 2011; 45: 1036-1044.

92 Maelfait J, Roose K, Bogaert P, et al. A20 (Tnfaip3) deficiency in myeloid cells protects against influenza A virus infection. PLoS Pathog 2012; 8: e1002570.

93 Snelgrove RJ, Goulding J, Didierlaurent AM, et al. A critical function for CD200 in lung immune homeostasis and the severity of influenza infection. Nat Immunol 2008; 9: 1074-1083.

94 Herold S, Mayer K, Lohmeyer J. Acute lung injury: how macrophages orchestrate resolution of inflammation and tissue repair. Front Immunol 2011; 2: 65.

95 Sica A, Mantovani A. Macrophage plasticity and polarization: in vivo veritas. J Clin Invest 2012; 122: 787-795.

96 Szretter KJ, Gangappa S, Lu X, et al. Role of host cytokine responses in the pathogenesis of avian H5N1 influenza viruses in mice. J Virol 2007; 81: 2736-2744.

97 Karupiah G, Chen JH, Mahalingam S, et al. Rapid interferon gamma-dependent clearance of influenza A virus and protection from consolidating pneumonitis in nitric oxide synthase 2-deficient mice. J Exp Med 1998; 188: 1541-1546.

98 Janssen WJ, Barthel, L, Muldrow A, et al. Fas determines differential fates of resident and recruited macrophages during resolution of acute lung injury. Am J Respir Crit Care Med 2011; 184: 547-560

99 Aldridge JR, Moseley CE, Boltz DA, et al. TNF/iNOS-producing dendritic cells are the necessary evil of lethal influenza virus infection. Proc Natl Acad Sci USA 2009; 106: 5306-5311.

100 Dawson TC, Beck MA, Kuziel WA, et al. Contrasting effects of CCR5 and CCR2 deficiency in the pulmonary inflammatory response to influenza A virus. Am J Pathol 2000; 156: 1951-1959.

101 Lin KL, Suzuki Y, Nakano H, et al. CCR2+ monocyte-derived dendritic cells and exudate macrophages produce influenza-induced pulmonary immune pathology and mortality. J Immunol 2008; 180: 2562-2572.

102 Lin KL, Sweeney S, Kang BD, et al. CCR2-antagonist prophylaxis reduces pulmonary immune pathology and markedly improves survival during influenza infection. J Immunol 2011; 186: 508-515.

103 Wang J, Li F, Sun R, et al. Bacterial colonization dampens influenza-mediated acute lung injury via induction of M2 alveolar macrophages. Nat Commun 2013; 4: 2106.

104 Capelozzi VL, Parra ER, Ximenes M, et al. Pathological and ultrastructural analysis of surgical lung biopsies in patients with swine-origin influenza type A/H1N1 and acute respiratory failure. Clinics (Sao Paulo) 2010; 65: 1229-1237. 
Korteweg C, Gu J. Pathology, molecular biology, and pathogenesis of avian influenza A (H5N1) infection in humans. Am J Pathol 2008; 172: 1155-1170.

Martin TR, Hagimoto N, Nakamura M, et al. Apoptosis and epithelial injury in the lungs. Proc Am Thorac Soc 2005; 2: 214-220.

Högner K, Wolff T, Pleschka S, et al. Macrophage-expressed IFN- $\beta$ contributes to apoptotic alveolar epithelial cell injury in severe influenza virus pneumonia. PLoS Pathog 2013; 9: e1003188.

Herold S, Steinmueller M, von Wulffen W, et al. Lung epithelial apoptosis in influenza virus pneumonia: the role of macrophage-expressed TNF-related apoptosis-inducing ligand. J Exp Med 2008; 205: 3065-3077.

Rodrigue-Gervais IG, Labbé K, Dagenais M, et al. Cellular inhibitor of apoptosis protein cIAP2 protects against pulmonary tissue necrosis during influenza virus infection to promote host survival. Cell Host Microbe 2014; 15: $23-35$.

Desch AN, Randolph GJ, Murphy K, et al. $\mathrm{CD}_{103^{+}}$pulmonary dendritic cells preferentially acquire and present apoptotic cell-associated antigen. J Exp Med 2011; 208: 1789-1797.

influenza virus infection. J Clin Invest 2012; 122: 4037-4047.

Ichinohe T, Pang IK, Kumamoto Y, et al. Microbiota regulates immune defense against respiratory tract influenza A virus infection. Proc Natl Acad Sci USA 2011; 108: 5354-5359. pneumonia. J Clin Invest 2012; 122: 3652-3664.

GeurtsvanKessel CH, Willart MA, van Rijt LS, et al. Clearance of influenza virus from the lung depends on

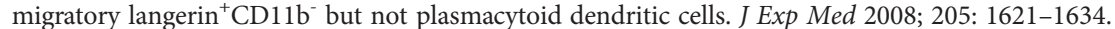

Kim TS, Braciale TJ. Respiratory dendritic cell subsets differ in their capacity to support the induction of virus-specific cytotoxic $\mathrm{CD}^{+}{ }^{+} \mathrm{T}$ cell responses. PLoS One 2009; 4: e4204.

Topham DJ, Tripp RA, Doherty PC. CD8 ${ }^{+} \mathrm{T}$ cells clear influenza virus by perforin or Fas-dependent processes. J Immunol 1997; 159: 5197-5200.

Brincks EL, Katewa A, Kucaba TA, et al. CD8T cells utilize TRAIL to control influenza virus infection. J Immunol 2008; 181: 4918-4925.

Kim TS, Sun J, Braciale TJ. T cell responses during influenza infection: getting and keeping control. Trends Immunol 2011; 32: 225-231.

Hufford MM, Kim TS, Sun J, et al. Antiviral $\mathrm{CD}^{+} \mathrm{T}$ cell effector activities in situ are regulated by target cell type. J Exp Med 2011; 208: 167-180.

Hufford MM, Richardson G, Zhou H, et al. Influenza-infected neutrophils within the infected lungs act as antigen presenting cells for anti-viral CD8 ${ }^{+}$T cells. PLoS One 2012; 7: e46581.

McGill J, Van Rooijen N, Legge KL. Protective influenza-specific CD8 T cell responses require interactions with dendritic cells in the lungs. J Exp Med 2008; 205: 1635-1646.

McGill J, Van Rooijen N, Legge KL. IL-15 trans-presentation by pulmonary dendritic cells promotes effector CD8 T cell survival during influenza virus infection. J Exp Med 2010; 207: 521-534.

Kim TS, Gorski SA, Hahn S, et al. Distinct dendritic cell subsets dictate the fate decision between effector and memory $\mathrm{CD}^{+} \mathrm{T}$ cell differentiation by a CD24-dependent mechanism. Immunity 2014; 40: 400-413.

Teijaro JR, Walsh KB, Cahalan S, et al. Endothelial cells are central orchestrators of cytokine amplification during influenza virus infection. Cell 2011; 146: 980-991.

Huang F, Guo J, Zou Z, et al. Angiotensin II plasma levels are linked to disease severity and predict fatal outcomes in H7N9-infected patients. Nat Commun 2014; 5: 3595.

Zou Z, Yan Y, Shu Y, et al. Angiotensin-converting enzyme 2 protects from lethal avian influenza A H5N1 infections. Nat Commun 2014; 5: 3594.

Berri F, Rimmelzwaan GF, Hanss M, et al. Plasminogen controls inflammation and pathogenesis of influenza virus infections via fibrinolysis. PLoS Pathog 2013; 9: e1003229.

Khoufache K, Berri F, Nacken W, et al. PAR1 contributes to influenza A virus pathogenicity in mice. J Clin Invest 2013; 123: 206-214.

Tsai SY, Segovia JA, Chang TH, et al. DAMP molecule S100A9 acts as a molecular pattern to enhance inflammation during influenza A virus infection: role of DDX21-TRIF-TLR4-MyD88 pathway. PLoS Pathog 2014; 10: e1003848.

Monsalvo AC, Batalle JP, Lopez MF, et al. Severe pandemic $2009 \mathrm{H} 1 \mathrm{~N} 1$ influenza disease due to pathogenic immune complexes. Nat Med 2011; 17: 195-199.

Brandes M, Klauschen F, Kuchen S, et al. A systems analysis identifies a feedforward inflammatory circuit leading to lethal influenza infection. Cell 2013; 154: 197-212.

Sakai S, Kawamata H, Mantani N, et al. Therapeutic effect of anti-macrophage inflammatory protein 2 antibody on influenza virus-induced pneumonia in mice. J Virol 2000; 74: 2472-2476.

Ichikawa A, Kuba K, Morita M, et al. CXCL10-CXCR3 enhances the development of neutrophil-mediated fulminant lung injury of viral and nonviral origin. Am J Respir Crit Care Med 2013; 187: 65-77.

Cameron CM, Cameron MJ, Bermejo-Martin JF, et al. Gene expression analysis of host innate immune responses during lethal H5N1 infection in ferrets. J Virol 2008; 82: 11308-11317.

Tate MD, Ioannidis LJ, Croker B, et al. The role of neutrophils during mild and severe influenza virus infections of mice. PLoS One 2011; 6: e17618.

Ljungman P, de la Camara R, Perez-Bercoff L, et al. Outcome of pandemic H1N1 infections in hematopoietic stem cell transplant recipients. Haematologica 2011; 96: 1231-1235.

Waffarn EE, Baumgarth N. Protective B cell responses to flu - no fluke! J Immunol 2011; 186: 3823-3829.

Sridhar S, Begom S, Bermingham A, et al. Cellular immune correlates of protection against symptomatic pandemic influenza. Nat Med 2013; 19: 1305-1312.

Sun J, Madan R, Karp CL, et al. Effector T cells control lung inflammation during acute influenza virus infection by producing IL-10. Nat Med 2009; 15: 277-284.

Moser EK, Hufford MM, Braciale TJ. Late Engagement of CD86 after influenza virus clearance promotes recovery in a FoxP3 ${ }^{+}$regulatory T cell dependent manner. PLoS Pathog 2014; 10: e1004315.

Antunes I, Kassiotis G. Suppression of innate immune pathology by regulatory T cells during influenza A virus infection of immunodeficient mice. J Virol 2010; 84: 12564-12575. 
142 Sun K, Metzger DW. Inhibition of pulmonary antibacterial defense by interferon-gamma during recovery from influenza infection. Nat Med 2008; 14: 558-564.

143 Morens DM, Taubenberger JK, Fauci AS. Predominant role of bacterial pneumonia as a cause of death in pandemic influenza: implications for pandemic influenza preparedness. J Infect Dis 2008; 198: 962-970.

144 Sonnenberg GF, Fouser LA, Artis D. Border patrol: regulation of immunity, inflammation and tissue homeostasis at barrier surfaces by IL-22. Nat Immunol 2011; 12: 383-390.

145 Ivanov S, Renneson J, Fontaine J, et al. Interleukin-22 reduces lung inflammation during influenza A virus infection and protects against secondary bacterial infection. J Virol 2013; 87: 6911-6924.

146 Pociask DA, Scheller EV, Mandalapu S, et al. IL-22 is essential for lung epithelial repair following influenza infection. Am J Pathol 2013; 182: 1286-1296.

147 Guo H, Topham DJ. Interleukin-22 (IL-22) production by pulmonary natural killer cells and the potential role of IL-22 during primary influenza virus infection. J Virol 2010; 84: 7750-7759.

148 Aujla SJ, Chan YR, Zheng M, et al. IL-22 mediates mucosal host defense against Gram-negative bacterial pneumonia. Nat Med 2008; 14: 275-281.

149 Sonnenberg GF, Nair MG, Kirn TJ, et al. Pathological versus protective functions of IL-22 in airway inflammation are regulated by IL-17A. J Exp Med 2010; 207: 1293-1305.

150 Monticelli LA, Sonnenberg GF, Abt MC, et al. Innate lymphoid cells promote lung-tissue homeostasis after infection with influenza virus. Nat Immunol 2011; 12: 1045-1054

151 Jamieson AM, Pasman L, Yu S, et al. Role of tissue protection in lethal respiratory viral-bacterial coinfection. Science 2013; 340: 1230-1234.

152 Mock JR, Garibaldi BT, Aggarwal NR, et al. Foxp3 regulatory T cells promote lung epithelial proliferation. Mucosal Immunol 2014; 7: 1440-1451.

153 Herold S, Tabar TS, Janssen H, et al. Exudate macrophages attenuate lung injury by the release of IL-1 receptor antagonist in Gram-negative pneumonia. Am J Respir Crit Care Med 2011; 183: 1380-1390.

154 Narasaraju T, Ng HH, Phoon MC, et al. MCP-1 antibody treatment enhances damage and impedes repair of the alveolar epithelium in influenza pneumonitis. Am J Respir Cell Mol Biol 2010; 42: 732-743.

155 Mason RJ, Leslie CC, McCormick-Shannon K, et al. Hepatocyte growth factor is a growth factor for rat alveolar type II cells. Am J Respir Cell Mol Biol 1994; 11: 561-567.

156 Cakarova L, Marsh LM, Wilhelm J, et al. Macrophage tumor necrosis factor-alpha induces epithelial expression of granulocyte-macrophage colony-stimulating factor: impact on alveolar epithelial repair. Am J Respir Crit Care Med 2009; 180: 521-532.

157 Sturrock A, Seedahmed E, Mir-Kasimov M, et al. GM-CSF provides autocrine protection for murine alveolar epithelial cells from oxidant-induced mitochondrial injury. Am I Physiol Lung Cell Mol Physiol 2012; 302: L343-L351.

158 Leeman KT, Fillmore CM, Kim CF. Lung stem and progenitor cells in tissue homeostasis and disease. Curr Top Dev Biol 2014; 107: 207-233.

159 Desai TJ, Brownfield DG, Krasnow MA. Alveolar progenitor and stem cells in lung development, renewal and cancer. Nature 2014; 507: 190-194.

160 Kumar PA, Hu Y, Yamamoto Y, et al. Distal airway stem cells yield alveoli in vitro and during lung regeneration following H1N1 influenza infection. Cell 2011; 147: 525-538.

161 Zuo W, Zhang T, Wu DZ, et al. p63Krt5 distal airway stem cells are essential for lung regeneration. Nature 2015; 517: 616-620

162 Anikina AG, Shkurupii VA, Potapova OV, et al. Expression of profibrotic growth factors and their receptors by mouse lung macrophages and fibroblasts under conditions of acute viral inflammation in influenza A/H5N1 virus. Bull Exp Biol Med 2014; 156: 833-837.

163 Carlson CM, Turpin EA, Moser LA, et al. Transforming growth factor- $\beta$ : activation by neuraminidase and role in highly pathogenic H5N1 influenza pathogenesis. PLoS Pathog 2010; 6: e1001136.

164 Uyeki TM. Preventing and controlling influenza with available interventions. N Engl J Med 2014; 370: 789-791.

165 Ventetuolo CE, Muratore CS. Extracorporeal life support in critically ill adults. Am J Respir Crit Care Med 2014; 190: 497-508

166 Cortes Garcia M, Sierra Moros MJ, Santa-Olalla Peralta P, et al. Clinical characteristics and outcomes of diabetic patients who were hospitalised with 2009 pandemic influenza A H1N1 infection. J Infect 2012; 64: 218-224.

167 Morgan OW, Bramley A, Fowlkes A, et al. Morbid obesity as a risk factor for hospitalization and death due to 2009 pandemic influenza A(H1N1) disease. PLoS One 2010; 5: e9694.

168 Kourtis AP, Read JS, Jamieson DJ. Pregnancy and infection. N Engl J Med 2014; 370: 2211-2218.

169 Everitt AR, Clare S, Pertel T, et al. IFITM3 restricts the morbidity and mortality associated with influenza. Nature 2012; 484: 519-523.

170 Pinto LH, Lamb RA. Controlling influenza virus replication by inhibiting its proton channel. Mol Biosyst 2007; 3: $18-23$.

171 Bright RA, Shay DK, Shu B, et al. Adamantane resistance among influenza A viruses isolated early during the 2005-2006 influenza season in the United States. JAMA 2006; 295: 891-894.

172 Lackenby A, Thompson CI, Democratis J. The potential impact of neuraminidase inhibitor resistant influenza. Curr Opin Infect Dis 2008; 21: 626-638.

173 Thorlund K, Awad T, Boivin G, et al. Systematic review of influenza resistance to the neuraminidase inhibitors. BMC Infect Dis 2011; 11: 134 .

174 Jefferson T, Jones M, Doshi P, et al. Neuraminidase inhibitors for preventing and treating influenza in healthy adults: systematic review and meta-analysis. BMJ 2009; 339: b5106.

175 Jefferson T, Jones MA, Doshi P, et al. Neuraminidase inhibitors for preventing and treating influenza in healthy adults and children. Cochrane Database Syst Rev 2014; 4: CD008965.

176 Louie JK, Yang S, Acosta M, et al. Treatment with neuraminidase inhibitors for critically ill patients with influenza A (H1N1)pdm09. Clin Infect Dis 2012; 55: 1198-1204.

177 Beyleveld G, White KM, Ayllon J, et al. New-generation screening assays for the detection of anti-influenza compounds targeting viral and host functions. Antiviral Res 2013; 100: 120-132.

178 De Clercq E. Acyclic nucleoside phosphonates: past, present and future. Bridging chemistry to HIV, HBV, HCV, HPV, adeno-, herpes-, and poxvirus infections: the phosphonate bridge. Biochem Pharmacol 2007; 73: 911-922. 
Furuta Y, Gowen BB, Takahashi K, et al. Favipiravir (T-705), a novel viral RNA polymerase inhibitor. Antiviral Res 2013; 100: 446-454.

Moss RB, Hansen C, Sanders RL, et al. A phase II study of DAS181, a novel host directed antiviral for the treatment of influenza infection. J Infect Dis 2012; 206: 1844-1851.

Belser JA, Lu X, Szretter KJ, et al. DAS181, A novel sialidase fusion protein, protects mice from lethal avian influenza H5N1 virus infection. J Infect Dis 2007; 196: 1493-1499.

Hui DS, Lee N. Adjunctive therapies and immunomodulating agents for severe influenza. Influenza Other Respir Viruses 2013; 7: Suppl. 3, 52-59.

Enserink M. Infectious disease. Old drugs losing effectiveness against flu; could statins fill gap? Science 2005; 309: 1976-1977.

Radigan KA, Urich D, Misharin AV, et al. The effect of rosuvastatin in a murine model of influenza A infection. PLoS One 2012; 7: e35788.

Truwit JD, Bernard GR, Steingrub J, et al. Rosuvastatin for sepsis-associated acute respiratory distress syndrome. N Engl J Med 2014; 370: 2191-2200.

Ludwig S. Targeting cell signalling pathways to fight the flu: towards a paradigm change in anti-influenza therapy. J Antimicrob Chemother 2009; 64: 1-4. NF-кB-inhibiting activity. Cell Microbiol 2007; 9: 1683-1694.

Droebner K, Pleschka S, Ludwig S, et al. Antiviral activity of the MEK-inhibitor U0126 against pandemic H1N1v and highly pathogenic avian influenza virus in vitro and in vivo. Antiviral Res 2011; 92: 195-203.

Herold S, Hoegner K, Vadãsz I, et al. Inhaled granulocyte/macrophage colony-stimulating factor as treatment of pneumonia-associated acute respiratory distress syndrome. Am J Respir Crit Care Med 2014; 189: 609-611.

Recommended composition of influenza virus vaccines for use in the 2014-2015 northern hemisphere influenza season. Wkly Epidemiol Rec 2014; 89: 93-104.

Grohskopf LA, Olsen SJ, Sokolow LZ, et al. Prevention and control of seasonal influenza with vaccines: recommendations of the Advisory Committee on Immunization Practices (ACIP) - United States, 2014-15 influenza season. MMWR Morb Mortal Wkly Rep 2014; 63: 691-697.

Madhi SA, Cutland CL, Kuwanda L, et al. Influenza vaccination of pregnant women and protection of their infants. N Engl J Med 2014; 371: 918-931.

Morens DM, Subbarao K, Taubenberger JK. Engineering H5N1 avian influenza viruses to study human adaptation. Nature 2012; 486: 335-340.

Shultz LD, Brehm MA, Garcia-Martinez JV, et al. Humanized mice for immune system investigation: progress, promise and challenges. Nat Rev Immunol 2012; 12: 786-798.

Scannell JW, Blanckley A, Boldon H, et al. Diagnosing the decline in pharmaceutical R\&D efficiency. Nat Rev Drug Discov 2012; 11: 191-200.

Ludwig S, Zell R, Schwemmle M, et al. Influenza, a one health paradigm - novel therapeutic strategies to fight a zoonotic pathogen with pandemic potential. Int J Med Microbiol 2014; 304: 894-901.

Shirey KA, Lai W, Scott AJ, et al. The TLR4 antagonist eritoran protects mice from lethal influenza infection. Nature 2013; 497: 498-502.

8 Imai $\mathrm{Y}$, Kuba K, Rao $\mathrm{S}$, et al. Angiotensin-converting enzyme 2 protects from severe acute lung failure. Nature 2005; 436: 112-116.

Karlstrom A, Boyd KL, English BK, et al. Treatment with protein synthesis inhibitors improves outcomes of secondary bacterial pneumonia after influenza. J Infect Dis 2009; 199: 311-319.

Morita M, Kuba K, Ichikawa A, et al. The lipid mediator protectin D1 inhibits influenza virus replication and improves severe influenza. Cell 2013; 153: 112-125.

Croft M. The role of TNF superfamily members in T-cell function and diseases. Nat Rev Immunol 2009; 9: 271-285. 